* Corresponding author E-mail address: jaroslav.homisin@tuke.sk (Jaroslav Homišin, prof., Ing., CSc.)

Article information

Article history: AMS-Volume15-No.3-00122-11 Received 12 April 2011

Accepted 12 May 201

\section{Selection of Wood Waste Chipper Drive Located on Automobile Chassis}

\author{
Jaroslav Homišin
}

Department of Machine Design, Transport and Logistics - Section of Machine Design and Machine Parts, Faculty of Mechanical Engineering, Technical University of Košice, Letná 9, 04001 Košice, Slovakia

\section{BIOGRAPHICAL NOTES}

prof. Ing. Jaroslav Homišin, CSc. Mr. prof. J. Homišin is a university professor nominated in the branch of science "Machine Parts and Mechanisms of Machines" with professional specialisation oriented to: optimisation of torsionally oscillating mechanical systems with an accent to the control of dangerous torsional oscillations by means of application of flexible shaft couplings, namely by pneumatic flexible shaft couplings; diagnostics of torsionally oscillating mechanical systems performed with regard to the characteristics of torsional oscillation and excited mechanical oscillation. Results of his scientific-research activities are summarized in more than 150 original scientific works published in domestic and foreign professional journals, as well as in the form of profes-sional articles presented in many scientific conferences and symposiums at home and abroad. He is owner of 32 technical patents. There are also another important and relevant publication out-puts of his professional life: 2 domestic monographs, 1 foreign monograph, 4 university textbooks and several study textbooks.

\section{KEY WORDS}

Control of Torsional Vibration, Detailed Dynamic Analysis, Appropriate Tuning of Mechanical systems

\section{ABSTRACT}

The aim of every designer is to reduce the size of torsional vibration in any mechanical system. Successful control of torsional vibration can be achieved only if a detailed analysis, computation of system in terms of torsional dynamics. The test results indicate that the intended objective can be achieved only if, some members of the system parameters are properly adapted to the dynamics of the system itself. This means that any torsionally oscillating mechanical system should be properly tuned. Therefore, the aim of Article will be to present and confirm an appropriate choice of wood waste chipper drive located on the automobile chassis based on a detailed dynamic analysis of Campbell diagrams and amplitude-frequency characteristics.

\section{Introduction}

Pumps, fans, but especially internal combustion engines and compressors, exciters are of torsional vibrations in mechanical systems. Intensive torsional vibration causes excessive stress in these dynamic systems. As a consequence, there comes to failure of individual components of mechanism, such as bearings, shafts, gears, flexible shaft couplings and eventually also piston devices. Hence the need to control dangerous torsional vibration of mechanical systems is becoming increasingly greater.

At present, biomass is belongs to the most important renewable energy sources. 
For processing of biomass are used different types of wood chippers and shredders adapted for heavy forestry and agricultural equipment. Since the wood chippers are periodically operating machines, they bring into the system adverse torsional vibration.

Successful control of torsional vibration can be achieved only in the case of a detailed analysis and calculation of the system in terms of torsional dynamics $[1,2,12]$. The test results indicate that the intended objective can be achieved only if, some members of the system parameters are appropriately adapted the dynamics of the system itself. This means that any torsionally oscillating mechanical system (TOMS) must be properly tuned in advance [3].

Therefore, the aim of Article will be to present and confirm an appropriate choice of wood waste chipper drive located on the automobile chassis based on a detailed dynamic analysis of Campbell diagrams and amplitude-frequency characteristics.

\section{Representation of Variables and Results SBRA}

Requirements for device:

- wood waste chipper on the performance of $P=45 \div 55 \mathrm{~m}^{3} / \mathrm{h}$,

- hydraulic feeder for the mechanical wood feeding,

- collection container with self-emptying system,

- placement on the chassis of IVECO Trakker AD 380T44W.

Based on the survey and subsequent analysis of the available commercial chippers wood waste up to power $60 \mathrm{~m}^{3} / \mathrm{h}$, with representation in Slovakia, based on specified parameters was selected as the best alternative a mobile chipper HEM 360 Z, of a German producer JENZ (Fig. 1) with technical parameters according to Tab.1.

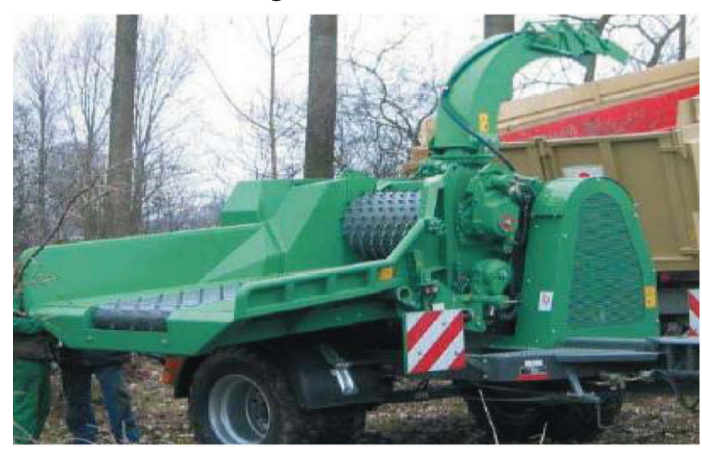

Fig. 1: HEM 360 Z mobile chipper.
Table 1: Technical parameters HEM 360 Z chipper.

\begin{tabular}{|c|c|}
\hline $\begin{array}{c}\text { maximum engine power }[\mathrm{kW}] \\
\text { maximum performance of wood } \\
\text { chipper }\left[\mathrm{m}^{3} / \mathrm{h}\right]\end{array}$ & 60 \\
\hline diameter of cutting drum $[\mathrm{mm}]$ & 520 \\
\hline maximum size of wood $[\mathrm{mm}]$ & $\begin{array}{c}260 \mathrm{soft} / \\
370 \text { hard }\end{array}$ \\
\hline $\begin{array}{c}\text { wood chipper dimensions } 1 \times \mathrm{w} \times \\
\mathrm{h}[\mathrm{m}]\end{array}$ & \begin{tabular}{c}
$4.8 \times 2.55 \times 3.9$ \\
\hline total machine weight $[\mathrm{kg}]$
\end{tabular} \\
\hline
\end{tabular}

\section{Conceptual Design of Vehicle, Power Take off and Drive of Wood Chipper}

Design of appropriate alternatives of wood chipper drives depends on the solution of vehicle concept itself ${ }^{\prime}$ which must respect the Law. 116/1997 on the conditions of traffic of vehicles on roads.

\section{Alternative designs of vehicle concept}

In practical terms, the chipper can be placed on automobile chassis in two alternatives:

- In the front of the chassis storage area with control in the vehicle cab,

- In the rear of the chassis storage area with control outside the vehicle cab.

\section{Power take off design}

In terms of simplicity and reliability is best to implement power take off from the rear of the engine with the adapter from the axis of the internal combustion engine crankshaft.

Based on the advantages and disadvantages of various alternatives, as well as sampling of power take off, the more suitable alternative location of wood chipper is in front of the vehicle (Fig. 2), with power take off from the rear of the engine.

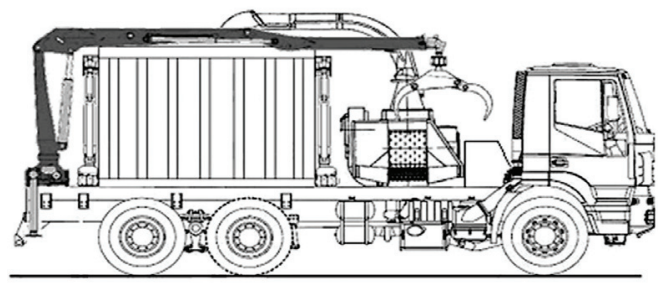

Fig. 2: The final concept of vehicle.

\section{Design alternatives of wood chipper drive}

A. power output from the engine, flexible connection and speed reduc-tion with V-belts (Fig. 3).

The design is simple and constructionally easy. An advantage are the good damping properties of flex 
ible couplings Flender Elpex EST-S 290 and V-belts. Resulting that excessive load is of the system is damped. The big disadvantage is the high load force of bearings with additional radial forces from the belt tension.

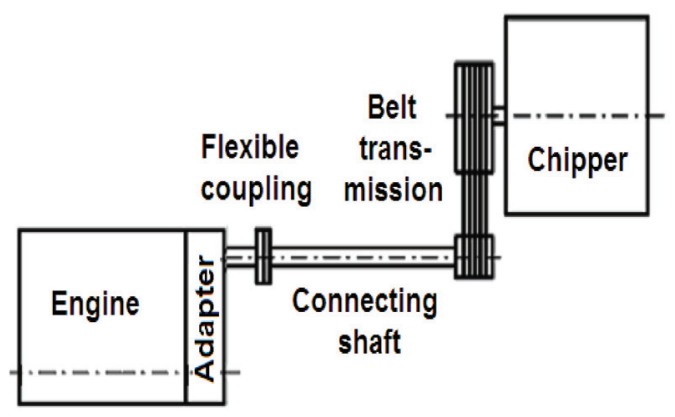

Fig. 3: Drive scheme of power take off shaft with V-belt transmission.

- flexible connection with belt transmission using narrow $V$-belts:

$\checkmark$ transmitted power $P=150 \mathrm{~kW}$,

$\checkmark$ crankshaft speed $n_{m}=1350 \mathrm{~min}^{-1}$,

$\checkmark$ flexible coupling EST 290: $k_{\varphi}=3,6.103$ N. $\mathrm{m}^{-\mathrm{rad}^{-1}}$; $\psi=0,8$,

$\checkmark$ belt type SPC according to ISO 4184 (DIN 7753): $k_{r}=$ 75549 N.m.rad ${ }^{-1}$, slip - 6\%, efficiency-81,5\%,

$\checkmark$ number of belts -4 ,

$\checkmark$ transmission ratio - 1,682.

- flexible connection with belt transmission using toothed belt:

$\checkmark$ transmitted power $P=150 \mathrm{~kW}$,

$\checkmark$ crankshaft speed $n_{m}=1350 \mathrm{~min}^{-1}$,

$\checkmark$ flexible coupling EST 290: $k_{\varphi}=3,6.103 \mathrm{~N} \cdot \mathrm{m} \mathrm{rad}^{-1}$; $\psi=0,8$,

- belt type PolyChain 14MGT2: $k_{r}=336418$ N.m.rad ${ }^{-1}$, efficiency-98\%,

$\checkmark$ number of belt teeth -170 ,

$\checkmark$ transmission ratio $-1,682$.

B. power output from the engine to gear reducer, flexible connection of cardan shaft with highly-flexible couplings (Fig. 4)

Design solution more expensive to the previous, but allows to transmit high torque without slipping, and for small angle of cardan shaft doesn't excessively load the bearings with additional radial forces.

By suitable stiffness of Flender flexible couplings type Elpex S-290 and EST ESNW 320 the torsionally oscillating mechanical system can be suitably tuned $[1,2,5,11,12]$.
- flexible connection with single-stage gearbox G02 Cl 200 of Rossi Moto-riduttori company:

$\checkmark$ transmitted power $P=150 \mathrm{~kW}$,

$\checkmark$ crankshaft speed $n_{m}=1350 \mathrm{~min}^{-1}$,

$\checkmark$ flexible coupling after engine EST 290: $k_{\varphi}=3,6.103$

N.m.rad ${ }^{-1} ; \psi=0,8$,

$\checkmark$ flexible coupling before chipper ESNW 320: $k_{\varphi}=$ $10.103 \mathrm{~N} \cdot \mathrm{m}_{\mathrm{rad}}{ }^{-1} ; \psi=1,15$,

$\checkmark$ transmission ratio - 1,768.

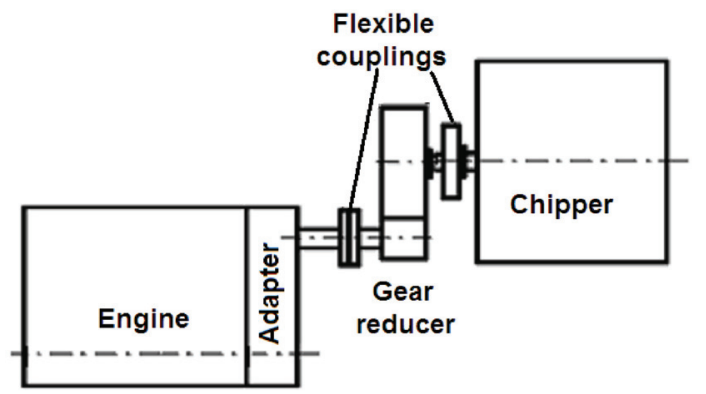

Fig. 4: Scheme of flexible coupling and gear reducer drive

\section{Dynamic Model wood Chipper Drive System}

In determining the dynamic drive system model of wood chipper we assume the wood chipper drive kinematic scheme (Fig. 5), consisting of driving device presented by six-cylinder internal

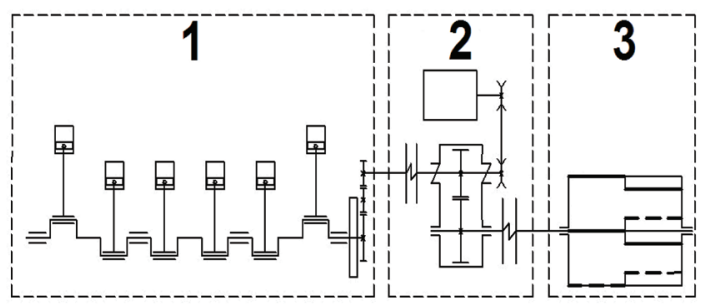

Fig. 5: Kinematic scheme of the wood chipper propulsion mechanical system.

combustion engine (1), the transmission device (2) and driven device presented by wood waste chipper (3).

Reduction of the rotating parts of the mechanical system kinematic scheme (Fig. 5) we get a threemass dynamic model of the system (Fig. 6) consisting of three rotating discs characterized by mass moment of inertia:

- six-cylinder internal combustion engine $I_{1}=4,07 \mathrm{~kg} \cdot \mathrm{m}^{2}$,

- transmission device for the case of: 
$\checkmark$ flexible connection of belt drive using narrow $V$-belts $I_{2}=6,68 \mathrm{~kg} \cdot \mathrm{m}^{2}$,

$\checkmark$ flexible connection of belt drive using toothed belt $I_{2}=0,56 \mathrm{~kg} \cdot \mathrm{m}^{2}$,

$\checkmark$ flexible connection of gear reducer $I_{2}=0,28 \mathrm{~kg} \cdot \mathrm{m}^{2}$,

- with rotating parts of wood waste chipper $I_{3}=23,109$ kg. $\mathrm{m}^{2}$,

- torsional stiffnesses $k_{12}$ and $k_{23}$ of flexible couplings and belt drives,

- damping properties $b_{12}$ and $b_{23}$ of flexible couplings.

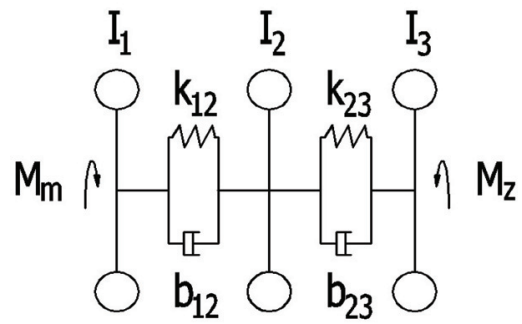

Fig. 6: Dynamic model the wood chipper drive system.

Drive system dynamic model of the wood chipper is described by a system of differential equations ( 1 2,3):

$I_{1} \cdot \ddot{\phi}_{1}+b_{12} \cdot\left(\dot{\phi}_{1}-\dot{\phi}_{2}\right)+k_{12} \cdot\left(\phi_{1}-\phi_{2}\right)$

$=M_{m}(t)$,

$I_{2} \cdot \ddot{\phi}_{2}+b_{12} \cdot\left(\dot{\phi}_{1}-\dot{\phi}_{2}\right)+b_{23} \cdot\left(\dot{\phi}_{2}-\dot{\phi}_{3}\right)$

$-k_{12} \cdot\left(\phi_{1}-\phi_{2}\right)+k_{23} \cdot\left(\phi_{2}-\phi_{3}\right)=0$,

$I_{3} \cdot \ddot{\phi}_{3}-b_{23} \cdot\left(\dot{\phi}_{2}-\dot{\phi}_{3}\right)-k_{23} \cdot\left(\phi_{2}-\phi_{3}\right)$

$=-M_{z}(t)$.

while driving torque of six-cylinder internal combustion engine is characterized by equation (4), and the excitation moment of the wood waste chipper is characterized by relation (5)

$$
\begin{aligned}
& M_{m}(t)=M_{m 0}+\sum_{\kappa=1}^{n} M_{m \kappa} \cdot \sin \left(\kappa \cdot \omega \cdot t+v_{\kappa}\right)(4) \\
& M_{Z}(t)=M_{Z 0}+\sum_{\kappa=1}^{n} M_{z k} \cdot \sin .
\end{aligned}
$$

Both moments are defined by medium torque $M_{m 0}$ and $M_{z 0}$ and non-variable with time in steadystate and amplitudes of harmonic components $M_{m k}$ and $M_{z K}$ of rank $k$.

By processing and determination of the drivin torque of the engine $M_{m}$ and exciting torque $M_{z}$ of wood waste chipper were calculated individual values of mean torque $M_{m 0}$ and $M_{z 0^{\prime}}$ values of harmonic components $M_{m k}$ a $M_{z k}$ and phases UK (Tab. 1 and Tab. 2).

Table 1 Values of the individual $U$ components of six-cylinder internal combustion engine driving torque $M_{m}$.

\begin{tabular}{|c|c|c|}
\hline $\begin{array}{c}\text { Rank of harmonic } \\
\text { component }\end{array}$ & $\begin{array}{c}\text { Amplitude } \mathbf{M}_{\mathbf{m} \mathbf{0}} \mathbf{a} \mathbf{M}_{\mathbf{m} \mathbf{K}} \\
(\mathbf{N} \cdot \mathbf{m})\end{array}$ & $\begin{array}{c}\text { Phase } U_{K} \\
\text { (rad) }\end{array}$ \\
\hline 0 & 2078,497 & 1,570796 \\
\hline 3 & 2187,022 & 6,133244 \\
\hline 6 & 1042,962 & 5,705516 \\
\hline 9 & 356,453 & 5,125887 \\
\hline 12 & 154,143 & 4,340151 \\
\hline
\end{tabular}

Table 2 Values of the individual components of wood waste chipper exciting torque $M_{\text {. }}$.

\begin{tabular}{|c|c|c|}
\hline $\begin{array}{c}\text { Rank of harmonic } \\
\text { component }\end{array}$ & $\begin{array}{c}\text { Amplitude } \mathbf{M}_{\mathbf{m} 0} \mathbf{a} \mathbf{M}_{\mathbf{m} K} \\
\text { (N.m) }\end{array}$ & $\begin{array}{c}\text { Phase } U_{K} \\
\text { (rad) }\end{array}$ \\
\hline 0 & 1400 & \\
\hline 4 & 599,442 & $-0,92092$ \\
\hline 8 & 485,808 & $-0,30763$ \\
\hline 12 & 324,935 & 0,311737 \\
\hline
\end{tabular}

\section{Dynamic Analysis Evaluation of the Wood Chippers Mechanical System Drive \\ 5.1 Alternative designs of vehicle concept}

When investigating a suitable tuning of any TOMS we use the Campbell diagram. It determines the critical speeds $n_{k}$ (eventually critical angular frequencies $\omega_{k}$ ) at the intersection of natural speed frequency lines $N$ (eventually natural angular frequencies $\Omega_{0}$ ) with the lines of harmonic components beam load torque. Orthogonal projection of the intersections in the horizontal axis indicates the position of the critical speed of the system $[3,6,7,10]$.

In general terms it can be stated that in the considered system are two of different exciters torsional oscillations, in the choice of working speed it is advantageous to as far as possible eliminate the dispersion of the major harmonic components. The result is a constant speed of crankshaft $n_{m}=$ 
$1350 \mathrm{~min}^{-1}$, where the chipper reaches speed about $n_{p}=1000 \mathrm{~min}^{-1}$. Both speed frequencies are in the range recommended by the manufacturer. From the dynamic point of view, the major harmonic components overlap in a small area, which practically reduces the number of critical speed in half, but with the effect that when they are reached the dynamic components of both torques are added together.

On Fig. 7 is presented the result of tuning the wood waste chipper mechanical system drive in the case of a flexible belt drive connection with the application of a narrow V-belts. Critical speed of 3-rd harmonic component of engine and 4-th harmonic component of load are by the idle engine speed $\left(n=\right.$ approximately 580 to $\left.600 \mathrm{~min}^{-1}\right)$, which the system overcomes during start-up. In the place of operating mode $n_{p}=1000 \mathrm{~min}^{-1}$ there is no intersection of natural speed frequencies with lines of load torque harmonic components. Based on that fact in terms of torsional vibration smooth running of chipper drive system can be concluded.

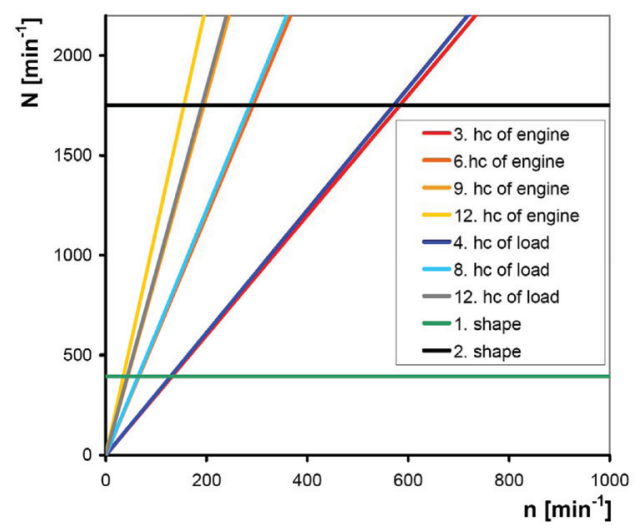

Fig. 7: Campbell diagram of chipper mechanical system drive with flexible coupling and narrow $V$-belt.

Figure 8 describes the result of tuning the wood waste chipper drive mechanical system in the case of belt transmission flexible connection with the application of toothed belt.

The resonance with the major harmonic components of engine torque excitation and load oc-curs in the speed area of approximately $n=100$ to 150 $\mathrm{min}^{-1}$. The system overcomes this area in a very short time at its start-up. The resonance with the minor harmonic (9-th from the engine and 12-th from the load) occurs at a speed $n=1180 \mathrm{~min}^{-1}$. This critical speeds in the dynamic terms are not as dangerous as the amplitude of the dynamic components because the torques are in this case quite low.

On Fig. 9 is presented the result of tuning the wood waste chipper mechanical system drive in the case of flexible connection of the gear reducer. The resonance with major harmonic components of engine and load torque excitation occurs in the idle speed range of engine $\left(n V=550 \mathrm{~min}^{-1}\right)$, which system overcomes at start-up of the device. Critical speed of the lower harmonics from the dynamic terms are not dangerous because they are in the start-up range of the system $\left(n=100 \div 300 \mathrm{~min}^{-1}\right)$ while the amplitude of the harmonic components are relatively low.

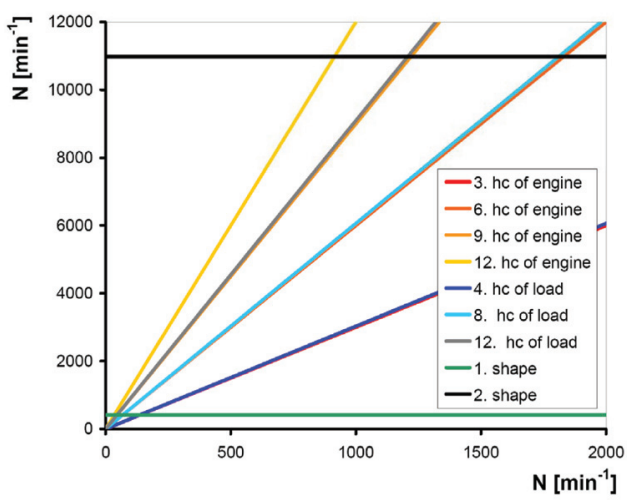

Fig. 8: Campbell diagram of chipper mechanical system drive with flexible coupling and toothed belt.

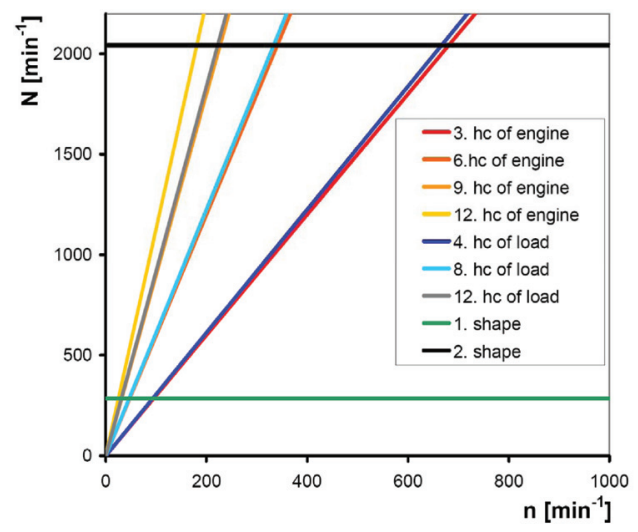

Fig. 9: Campbell diagram of chipper mechanical system drive with flexible connection of the gear reducer.

\subsection{Amplitude-Frequency Characteristics}

Amplitude-frequency characteristics (Fig. 10 and 11) are the result of the solution of differen-tial equations (1, 2 and 3$)$. 
Figures 10 and 11 present and characterize the results of solution as amplitude-frequency characteristics represented by dynamic load torque amplitude curves in speed range $[1,3,10]$.

The diagrams shows that the torsional stiffness of all three variants of chipper drive moved the natural speed frequencies to low values and thus system will work in the overcritical range.

From the diagrams it is obvious that close to the operating speed system $n_{p}=1000 \mathrm{~min}^{-1}$ no unde- sired torsional vibration system and therefore is not loaded with large dynamic component of torque.

Although the impact of all alternatives on the coupling behind the engine are the same, in the case before the wood chippers it appears preferable the alternative using highly-flexible couplings and reduction gear to an alternative with belts, because under such conditions there is significantly lowest dynamic component of the load torque acting in the system.

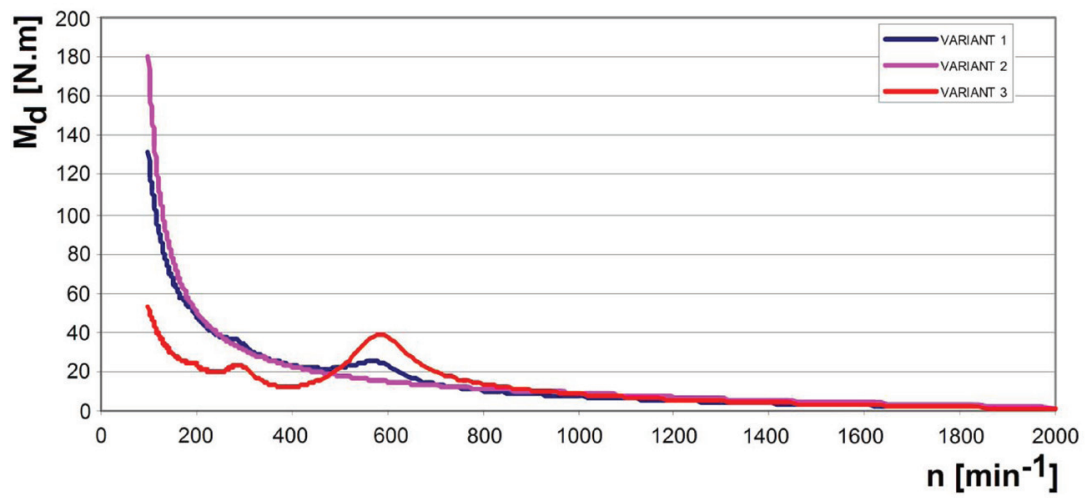

Fig. 10: Dynamic components of the engine torque load.

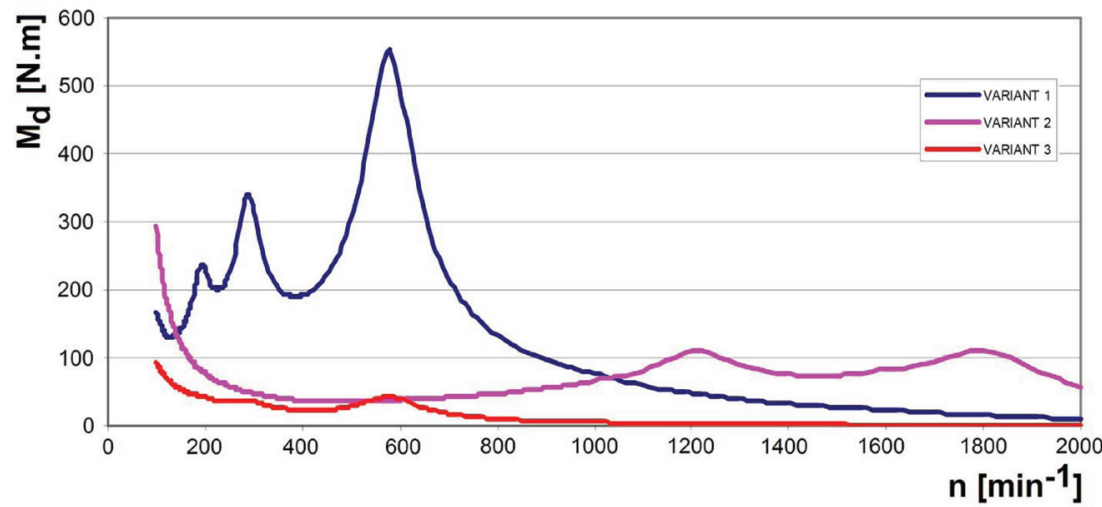

Fig. 11: Dynamic component of torque load before the wood chipper. tuning, thereby ensuring a sufficiently long lifetime

\section{Conclusion}

The result of works solution is the conceptual design the wood waste chipper car body, whose main goal was drive perceived both from a dynamic and structural point of view. This work high-lights the importance of simplicity and also importance of applications of flexible shaft couplings in the design of drives with Torsional vibration because they are simple and reliable way to ensure appropriate system of the device. Therefore, in solving the problem has been selected as the most appropriate alternative the drive with flexible couplings and gear reducer, compared to belt drives shafts and bearings are not loaded by exces-sive radial forces.

\section{Acknowledge}

This paper was written in the framework of Grant Project VEGA: 1/0304/09 "Go-verning of dangerous vibrations in drives of mechanical systems". 


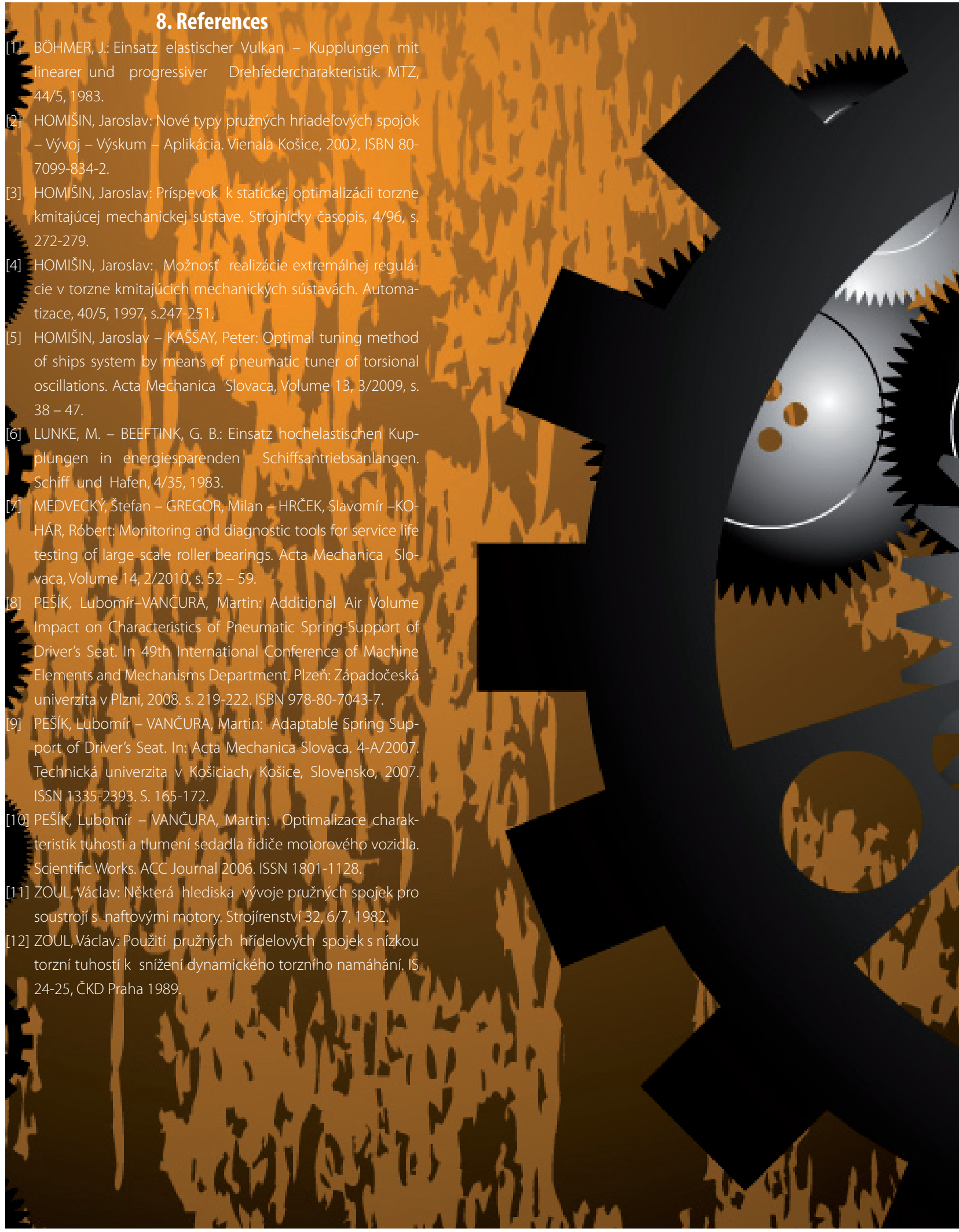

